\title{
Discussion on Sustainable Development Strategies of the Traditional Handicraft Industry Based on Su-Style Furniture in the Ming Dynasty
}

\author{
Kuo-Kuang Fan and Ting-Ting Feng * (] \\ Graduate School of Design, National Yunlin University of Science \&Technology, 123 University Road, Section 3, \\ Douliou 64002, Yunlin, Taiwan; fankk@gemail.yuntech.edu.tw \\ * Correspondence: fengtingting23@gmail.com; Tel.: +886-0903-783-706
}

Received: 20 January 2019; Accepted: 30 March 2019; Published: 4 April 2019

\begin{abstract}
The fabrication of traditional handicrafts is both an art creation activity and a social economic activity, meaning that the resulting works have dual artistic and economic characteristics. With the development of industrial mass production, the traditional handicraft industry is facing a series of challenges. For sustainable development of the traditional handicraft industry, first the establishment of its historical context and experience is necessary. Therefore, through an analysis of the competitive advantages of the Su-style furniture industry in the Ming Dynasty, this study first sorts out and summarizes the historical experience of the industry's successful development. Next, sustainable development strategies for the contemporary traditional handicraft industry are explored, and opinions on the inheritance and development of the traditional handicraft industry at the present stage are put forward. Based on the diamond model, this study of Su-style furniture in the Ming Dynasty shows that its competitive advantages in this period included style, material, and skill, and the contributions of the government and consumer demand played important roles in these competitive advantages. Therefore, the current development of the traditional handicraft industry requires both external heritage protection of the government and the internal transformation and innovation of the industry.
\end{abstract}

Keywords: traditional handicraft industry; sustainable development; Su-style furniture; industrial competitive advantages; diamond model

\section{Introduction}

The production of the traditional Chinese handicraft is not only an artistic activity of creation but also a social and economic activity. It is an important component of traditional culture. As the main mode of production in the pre-industrial era, the traditional handicraft itself carries abundant information about traditional cultural codes that embody the unique cultural connotation and value of traditional culture. Handicrafts, for many countries, remain important to the unique cultural heritage of the nation [1]. Therefore, the traditional handicraft industry occupies an important position in both cultural and artistic development and economic development.

The emergence of the Western industrial revolution changed people's mode of production and gradually formed the dividing line between "tradition" and "modern." With the continuous development of society, a large number of handicraft industries have transformed into machinery industries. Traditional handicraft industries have been greatly affected and are facing a series of challenges. At present, China is in a stage of rapid economic development. The social market economy is on the rise. The pace of people's lives is becoming faster, and the demand for material life is increasing. In the presence of efficient industrial production, the traditional handicraft industry has 
been pushed to the side. In 1989, the total international trade volume of handicraft products was USD 172.7 billion, accounting for $5.59 \%$ of the total international trade volume, while China's export volume was USD 2.7 billion, accounting for only $1.56 \%$ of the total international trade volume of handicraft products [2]. According to the first national census of the handicraft industry in 2008 (Figure 1), among the 1881 kinds of handicraft products in the national census, 988 (52.53\%) were in active development, 535 were struggling to survive, 244 were endangered, and 114 were discontinued [3]. In view of these dismaying results, the sustainable development of traditional crafts has become an important topic in China.

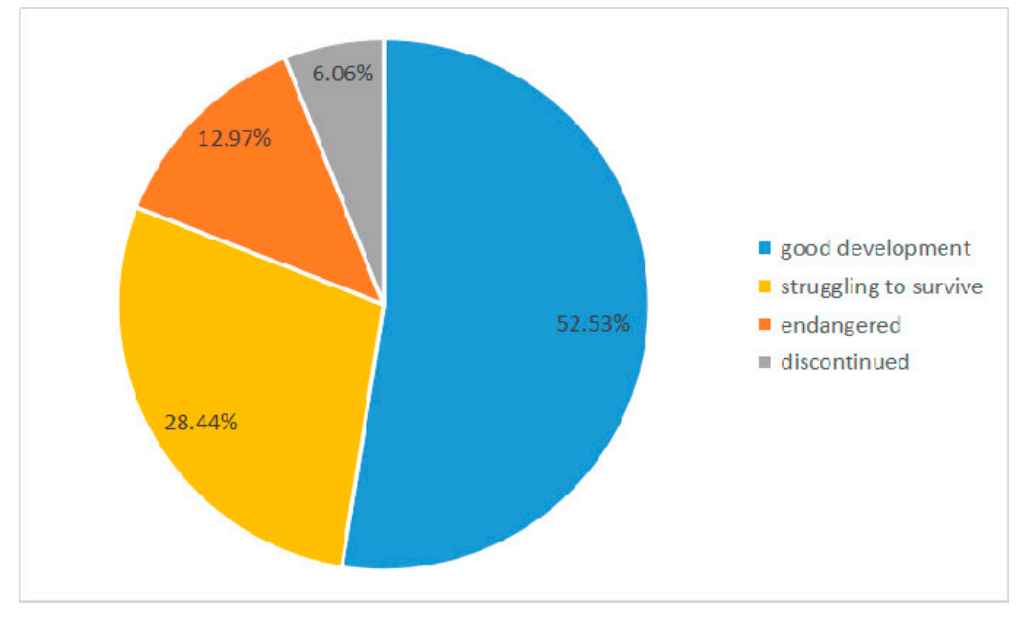

Figure 1. Results of the first national census of craft industry in 2008.

China established the Chinese Traditional Arts and Crafts Association in 1995, started the compilation of China Arts and Crafts Encyclopedia in 1996, and promulgated the Protection of Traditional Arts and Crafts in 1997. Internationally, the United Nations Educational, Scientific and Cultural Organization passed the Convention for the Safeguarding of the Intangible Cultural Heritage at its 32nd session in 2003. At the beginning of 2004, the Ministry of Culture launched a project to protect Chinese ethnic and folk cultural relics. Traditional handicrafts were included in the long-term development plan, which generated new circumstances for the comprehensive protection and research of traditional handicrafts. In the same year, China joined the Convention for the Safeguarding of the Intangible Cultural Heritage and became one of the earliest contracting parties. By 2015, traditional handicrafts had become an important focus within the scope of protection provided by the Convention. The Intangible Cultural Heritage Law of the People's Republic of China, which came into effect on 1 June 2011, has included tens of thousands of items of traditional handicraft projects in the protection lists of national, provincial, municipal, and county-level "Intangible Cultural Heritage" and opened up a new framework for the sustainable development of traditional handicrafts in China.

The sustainable development of the contemporary traditional handicraft industry requires, on the one hand, sorting out the experience during the development process in a historical context; on the other hand, it requires drawing on the research of different contemporary disciplines in a targeted way so that it can form the three-dimensional coordinates of vertical time and horizontal culture [4]. Among these factors, historical experience, as an important cultural resource, plays a key role in promoting the continuous development of traditional handicrafts. Therefore, this study puts traditional handicrafts into the overall context of history and culture. From the historical context perspective, by examining the historical experience of the competitive advantages of the Su-style furniture industry in the Ming Dynasty, this paper first provides a historical reference for the sustainable development of the current traditional handicrafts. Next, strategies for the sustainable development of contemporary traditional handicrafts are explored, and suggestions for the inheritance and development of the current traditional handicrafts are put forward. 


\section{Su-Style Furniture in the Ming Dynasty}

During the Ming Dynasty (1368-1644), commercial towns and capitalism sprouted in China. As one of the most prosperous countries in the world in terms of its commodity economy and handicraft industry, China has become the primary subject of historical research on the traditional handicraft industry. The furniture manufacturing industry in the Ming Dynasty yielded unique achievements in furniture history. The manufacturing process and craftsmanship reached the highest level at that time and occupied the peak position in the global furniture history. Its style and manufacturing methods are still in use today. The furniture of the Ming Dynasty has experienced sustainable development for hundreds of years, from ancient times to the present. Therefore, in the discussion of the sustainable development strategy for the current traditional handicraft industry, this study takes the furniture of the Ming Dynasty as the primary research subject and (1) analyzes the competitive advantages of the Ming Dynasty's furniture that enabled its long-term sustainable development and (2) summarizes its historical experience to provide a historical reference for the sustainable development of the traditional handicraft industry today.

In the Ming Dynasty, furniture was manufactured in many different regions, and the differences in geographical location, cultural background, and aesthetic habits led to different furniture styles. The furniture manufactured in the Jiangnan region, as represented by Suzhou, is regarded as the origin of Ming-style furniture. At present, Ming-style furniture generally refers to Su-style furniture from the Ming Dynasty. The Ming-style furniture manufactured in Suzhou is characterized by simple and elegant shapes, precious and high-quality materials, and reasonable size and structure; these characteristics are thus representative of the furniture manufactured during the Ming Dynasty. In 2006, Ming-style furniture was listed as China's first national intangible cultural heritage.

The earliest book that contains figures and texts about Ming-style furniture is the Lu Ban Jing Jiang Jia Jing, which consists of three volumes and was published in the Wanli Period (1572-1620) of the Ming Dynasty, with an addendum edited by Wu Rong. The book introduces the building process and living furniture and accurately depicts the shapes of various types of furniture [5]. This book specifies the furniture name, common practices, dimensions, and craft materials of the Ming Dynasty and provides furniture images. In 1944, Dr. Gustav Ecké (1896-1971) of Germany wrote a book called Chinese Domestic Furniture, which pioneered the modern research on Chinese Ming-style furniture. The book contains a total of 122 pieces of Ming-style furniture and describes the types, structures, materials, hardware accessories, and age identification of the furniture. Specifically, a large number of structural and scale drawings were guided by Dr. Gustav Ecké and drawn by Yang Yao [6]. Afterward, the Research on Ming-style Furniture by Yang Yao (1938-2017) first proposed to dividing the furniture into six categories according to function, namely, chairs, tables, cabinets, beds, platforms, and screens [7]. This function-based categorization method makes it easy to distinguish different furniture, and it has been followed by subsequent researchers of Ming-style furniture.

The works with far-reaching influence are the Research of Ming-style Furniture and Appreciation of Ming-style Furniture by Wang Shi-xiang (1914-2009). In the Research of Ming-style Furniture by Wang Shi-xiang, both broad and narrow concepts of Ming-style furniture are proposed. The broad concept of Ming-style furniture includes not only the furniture made during the Ming Dynasty but also furniture made of ordinary wood that was used for people's daily demands or made of precious wood and delicately carved. The furniture that is manufactured in contemporary and modern times with prominent Ming-style characteristics can be called Ming-style furniture. The narrow concept of Ming-style furniture refers to the beautiful and elegant furniture manufactured from the Ming Dynasty to the Qing Dynasty (1616-1912) [8] (p. 17). The Ming-style furniture discussed in this study is based on the narrow concept.

Suzhou is known as the origin of Ming-style furniture. The records of the popularity of fine wood furniture in the middle and late Ming Dynasty, as recorded by Fan Lian (1540-unknown) in Yun Jian Ju Mu Chao (1593), indicate that only celebrity nobles purchased desk and chair furniture made of fine wood from Suzhou (hardwood furniture made of dense wood). After the Longqing (1567-1572) and 
Wanli Periods, every family was using fine wood furniture [9]. Wang Shi-xiang (1547-1598) wrote in Guang Zhi Yi (1597) that the smart people in Suzhou fancied the ancient styles, and they were skilled at counterfeiting such ancient styles. All regions followed the preferences of Suzhou people regardless of elegance. Su-style furniture manufacturers preferred to use rosewood (Pterocarpus) and primitive simplicity instead of carving. When there were carvings, Su-style furniture manufacturers adopted the patterns of the Shang, Zhou, Qin and Han Dynasties. The whole country then emulated this furniture, which was especially popular in the Jiajing (1522-1566), Longqing, and Wanli Periods [10].

In Zun Sheng Ba Jian (1591), Gao Lian (unknown) mentioned that Suzhou's manufactured furniture, such as sofas, rattan chairs, and cattail chairs, was rather elegant and is applicable to modern times [11]. It was pointed out that the furniture styles in Suzhou were the most sophisticated, simple, and elegant and included many carvings; therefore, Su-style furniture was highly popular.

Su-style furniture is mostly light, simple, elegant, exquisite, and unsophisticated, with smooth lines and moderate proportions (Figure 2). Its makers are good at selecting materials; many precious hardwoods need to be transported or imported, so craftsmen particularly treasure these materials. They carefully calculate and plan for the use of the materials and cherish them as if they were gold, only starting fabrication after repeated and careful consideration. This kind of careful attention also makes the furniture simple and elegant in shape, differing from other styles that incorporate excessive carvings and decorations.

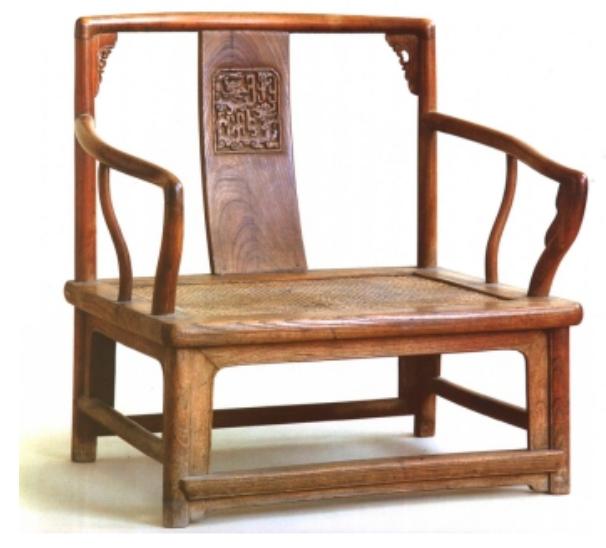

Figure 2. Beech low armchair in the Ming Dynasty. Wang Shi-xiang, Appreciation of Ming-style Furniture, SDX Joint Publishing Company \& Cultural Relics Publishing House, 1985.

At present, most research on the furniture of the Ming Dynasty focuses on the art style, production process, and age appreciation of the furniture, and such studies play a significant role in popularizing the style, decoration, structure, and materials of Ming-style furniture. However, research on the cultural, economic, and historical background still needs to be deepened.

\section{Dilemma of the Traditional Handicraft Industry}

\subsection{Challenges of Modern Technology}

Edward Lucie-Swith, a British scholar, divided the history of crafts into three historical stages. In the first stage, all articles were handicrafts, and all manufacturing processes were manually performed. All manufactured products, whether practical, religious, or decorative, were essentially handicrafts. In the second stage, during the European Renaissance, the distinction between handicrafts and fine arts was drawn. In the third stage, with the development of the industrial revolution, there appeared a difference between handicraft products and machine-made products [12].

The dilemma faced by the traditional handicraft industry has arisen from the transformation of the modern lifestyle, production diversity, dissemination diversity, and sales diversity. All these factors will lead to a reduction in demand for products of the traditional handicraft industry [1]. Mass 
production techniques have met the material needs of most people and created a series of new, cheaper, and easier-to-produce materials, such as metal and plastic materials, which have gradually replaced ceramics, wood, and other materials. Contrary to mass production, traditional craft practices have created a sustainable mode of material use that includes environmental friendliness [13]. However, the traditional handicraft industry is still unable to compete with the vigorous efficiency of industrial production because of its high-cost attributes, such as manpower, material resources, and time.

\subsection{Limitation of Inheritance}

As we all know, the inheritance mode of the ancient Chinese handicraft industry is different from that of other trades that are taught in schools. Instead, it involves family inheritance or mentorship inheritance within a strict hierarchical system with the characteristics of closeness and vulnerability. Family inheritance means that the younger generations inherit the craftsmanship of the older generations. On the basis of the familial relationship, craftsmanship is passed from generation to generation. The purpose of family inheritance is mostly to protect family interests and monopolize the technology; therefore, it is easy to lose certain crafts when the families who make them cease to exist, making family inheritance the inheritance mode with the greatest closeness and vulnerability among the types of traditional handicraft inheritance. Industrial inheritance is based on the master-apprentice relationship, in which the master passes all craftsmanship knowledge to one or more apprentices who, after they finish learning, can recruit new apprentices. Compared with family inheritance, mentorship inheritance partly alleviates the crisis of inheritance, but the different qualifications and talents of apprentices will weaken the competitiveness of the industry. Similar to the mentorship relationship in China, many artists in the Renaissance period worked as apprentices in handicraft workshops and received strict apprenticeship training and assessment. Some even worked for as long as several decades and were not allowed to marry until they became masters [14].

\subsection{Lack of Sustainable Development Policy}

Owing to the long learning time, low income, and demanding skills, many young people do not choose jobs related to traditional handicrafts but instead take jobs that are less strict and better paid [15]. By the end of 2012, there were about 3 million people working in the whole industry, and most traditional handicraft enterprises had fewer than 100 employees. Many old craftsmen have died, and those mastering intermediate and advanced techniques have changed to other jobs, resulting in the endangerment of many traditional handicrafts [16].

Although China has now enacted laws and regulations to protect and develop traditional handicrafts, the protections are still insufficient for traditional handicrafts with weak foundations. At present, the focus of laws and regulations lies in the protection and development of traditional handicrafts themselves, and the support for handicrafters is often lacking. Handicrafters form the main body of the sustainable development of traditional handicrafts, and any development measures should be implemented by handicrafters. Therefore, holding onto handicrafters is an urgent task in the sustainable development of traditional handicrafts.

\section{Methodology}

The Ming Dynasty's Su-style furniture, as a representative of the sustainable development of Chinese traditional handicrafts, has had unique competitive advantages in the development process for several hundred years. This study summarizes the historical trajectories and reasons of the sustainable development of the Su-style furniture of the Ming Dynasty and draws historical experience from them by analyzing its competitive advantages. By sorting out the historical context and experience, the study explores strategies for the sustainable development of contemporary traditional handicrafts. This study will collect, collate, and analyze literature related to the Su-style furniture of the Ming Dynasty from the five factors of the Michael Porter Diamond Model by streamlining the historical contexts of that dynasty. 
This study mainly uses first-hand materials with the support of the second-hand data. Therefore, most of the literature quoted is ancient texts, and local county annals.

The diamond model was proposed by Michael E. Porter in 1990. He believed that competitive advantages must be discussed from the perspective of four environmental factors: production factors; demand conditions; related industries and supporting industries; and corporate strategy, corporate structure, and peer competition [17].

1. Production factors, including economic and natural resources, are the initial advantages of sustainable industrial development.

2. Demand conditions are an important factor affecting the sustainable development of an industry, and it is also the most critical driving force in the industry's formation of competitive advantages.

3. Related industries and supporting industries refer to the related upstream and downstream industries that can promote the sustainable development of industries.

4. Peer competition refers to the benign competition and management mode formed in the industry.

In addition to the above four factors, government and opportunity also play an important supporting role (Figure 3).

5. Government and Opportunity

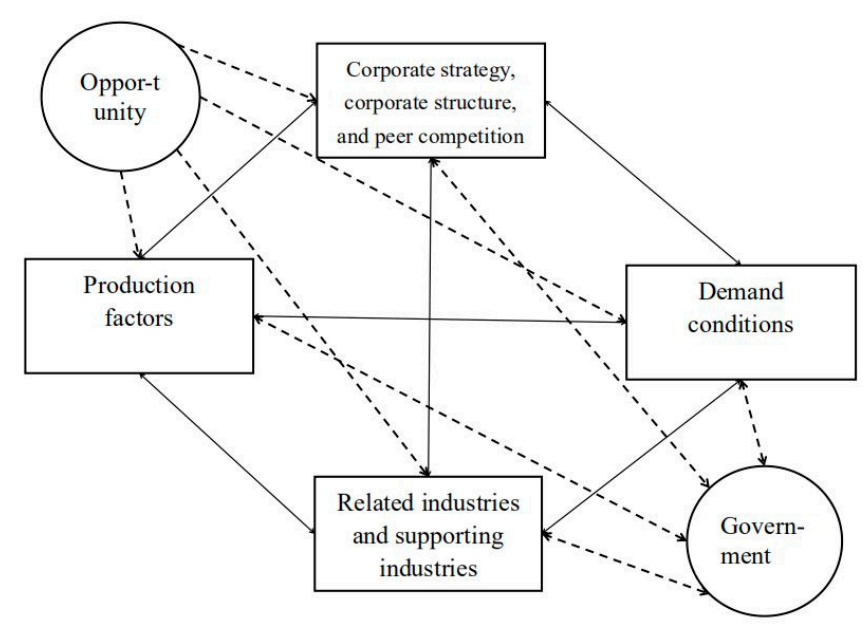

Figure 3. Diamond model. Michael E. Porter, Competitive Advantages of Countries, CITIC Press, 2012.

In this study, the two auxiliary factors, namely, government and opportunity, are integrated to form a relatively independent and complete auxiliary factor. A change in government policy can provide opportunities for the sustainable development of an industry. The government can also provide a sustainable social environment for industrial development.

The diamond model is a comprehensive industrial research method with a rigorous argument, which values theoretical thinking more. The competitive advantages are composed of multiple factors. In the model, factors seem to be separate, but they are closely related. Single factors cannot lead to complete competitive advantages. Moreover, the two auxiliary factors, "government" and "opportunity," play important roles. In different regions and under different time-and-space backgrounds and cultural backgrounds, the key factors vary. Therefore, the competitive advantages shown by the diamond model under different backgrounds are generally special and unique. This study seizes the feature of the diamond model and explores the sustainable development strategy for traditional handicrafts from a comprehensive perspective based on the current specific social and cultural backgrounds by analyzing the forming of the competitive advantages of the Su-style furniture of the Ming Dynasty. 


\section{Su-Style Furniture in Historical Context and the Sustainable Development of Traditional Furniture}

\subsection{Government and Opportunity}

\subsubsection{Eight-Part Essay Examination and Gardening Fashion}

Zhu Yuanzhang (1328-1398), the founder of the Ming Dynasty, established the imperial examination system to select officials after the founding of the state and he controlled the literati ideologically. In order to consolidate the regime, he even suppressed unfavorable thoughts and speeches, established literary inquisitions, and killed countless innocent literati [18]. Therefore, some literati chose not to take the examination or engage in an official career. With the prosperity of the commercial economy and the germination of capitalism in the Ming Dynasty, new social values were proposed among the people. Wang Yangming (1472-1529) put forward the "temperament theory," pointing out that "there is nothing beyond the heart"; thus, he focused on inner self-balance and pursued the nature of the inner self. For a period, the self-value of a large number of literati was awakened, breaking through the inherent thinking pattern, and people began to pursue individuality and affirm their "desires." In order to improve their living environment, many literati began to build their own gardens, which led to the rise of gardening fashion. In order to match the overall patterns and artistic conceptions of the gardens, most literati chose to design their own furniture for their gardens to realize the style and aesthetics that were the most compatible with the style of their own gardens (Figure 4). The literati became the most important designers and demanding consumers of furniture. The high standards and requirements for furniture products were also one of the reasons for the rapid development of furniture in the Ming Dynasty.

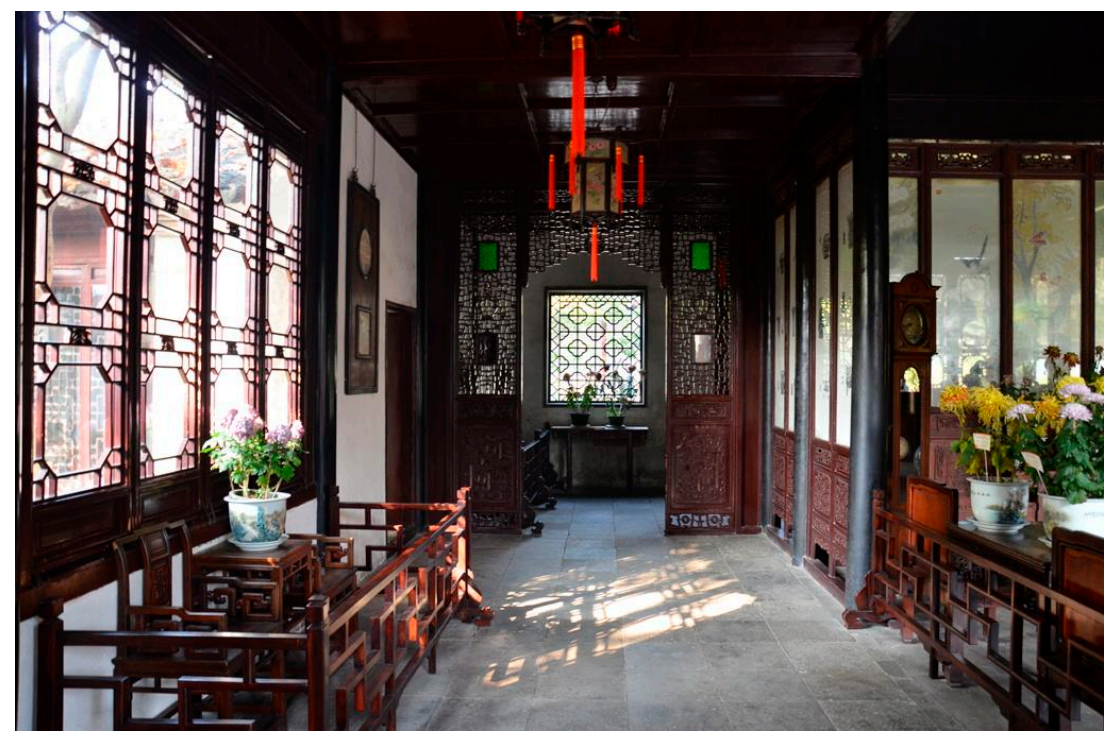

Figure 4. The Lingering Garden in Suzhou. Available online: https://you.ctrip.com/travels/jiangsu100066/ 2230387.html (3 April 2019).

\subsubsection{Reform of Craftsman System}

The management of craftsmen in the Ming Dynasty was subject to a clear craftsman registration system, and the imperial court set up the Ministry of Personnel, Ministry of Revenue, Ministry of Rites, Ministry of War, Ministry of Punishments, and Ministry of Works. Specifically, the minister of the Ministry of Revenue was in charge of the yellow registration system. According to the records of the yellow registration system. the handicraftsmen in the Ming Dynasty were incorporated into the craftsman registration and part of so-called craftsman households; once they were registered, they worked as craftsmen for generations [19]. 
In 1386, the government enacted the shift order, in which local craftsmen from all over the country were organized into several shifts by local governments and took turns serving in the capital. One shift lasted three years, and each service period lasted three months. In 1393, the shift period was also divided into different modes, including one shift for five years and one shift for one year, which were divided according to the type and complexity of the craftsman work [20].

However, it took a high amount of time for the craftsmen to travel to and from the capital over long distances. This shift system became the handicraft industry's labor system, which occupied the labor time of craftsmen and forced them to serve at their own expense, leading to slack work efforts and the escape of the craftsmen [21].

The long-term slack in work efforts and escape of craftsmen directly led to the low quality of finished products. With the development of a commodity economy and the circulation of silver ingots, in 1485 , the ruling class proposed a method of collecting silver ingots from craftsmen to replace their shifts [20].

The method of replacing shifts with silver ingots enabled the craftsmen to leverage the labor system, and more craftsmen returned to production. After the Jiajing Period, $80 \%$ of the craftsmen in the country basically worked freely [22].

\subsubsection{Ban on Maritime Trade and the Grand Voyages of Zheng He}

The ban on maritime trade meant that people were not allowed to trade with overseas countries without official permission. During the Hongwu Period, Japanese civilians who were plagued by the Japanese Civil War fled to China by sea, and these increasingly stronger Japanese pirates harassed and looted the coastal areas. From 1370 to 1374, Zhu Yuanzhang ordered the closure of the Bureau for Foreign Shipping (the customs institution today) of Taicang, Huangdu, Quanzhou, Mingzhou, and Guangzhou. In 1381, all officials and residents were banned from private trade with foreign countries. In 1384, to prevent attacks by Japanese pirates, fishermen were prohibited from fishing in the sea [23].

After Zhu Di (1360-1424) succeeded to the throne, he resumed the Bureau for Foreign Shipping, which had been abandoned by Zhu Yuanzhang, relaxed the ban on maritime trade, and gave emissaries preferential treatment. Although Zhu Di resumed the Bureau for Foreign Shipping, he only relaxed the ban on maritime trade instead of abolishing it.

In 1405, Zhu Di dispatched Zheng He (1371-1433) for six large-scale maritime trips in a row. On the seventh trip, he set off in the Xuande Period. The grand voyages of Zheng He promoted the maritime navigation development cause of ancient China. In an unprecedented feat in global navigation history, more than 27,000 people and 200 ships of various sizes were engaged in every trip. These efforts expanded the territory of overseas trade in the Ming Dynasty, as well as strengthened the economic and cultural exchanges and the development of China and foreign countries. As a consequence of people's fierce resistance and changes in foreign situations, the ban on maritime trade in the Ming Dynasty was finally abolished during the Longqing Period, which imparted China's overseas trade with far-reaching influence. The lift of the ban on maritime trade in the Ming Dynasty and the resumption of overseas trade brought Su-style furniture into a new stage of using precious hardwood, thus forming a leap forward in development.

From the analysis of the government and opportunity of the competitive advantages of Su-style furniture of the Ming Dynasty, we can see that the governmental function is the basic factor supporting the sustainable development of the industry. Although the government of the Ming Dynasty did not directly support the furniture, it provided policy support for its own sustainable development. On the basis of current national conditions, the traditional handicraft industry is strongly supported by the government. From the viewpoint of sustainability, the principle of sustainable development is "protection first, rational development, scientific planning, sustainable utilization." Protection is the premise of development, and development is the foundation of protection: together, they form a benign circle of development (Figure 5) and establish a sustainable development strategic system [24]. 


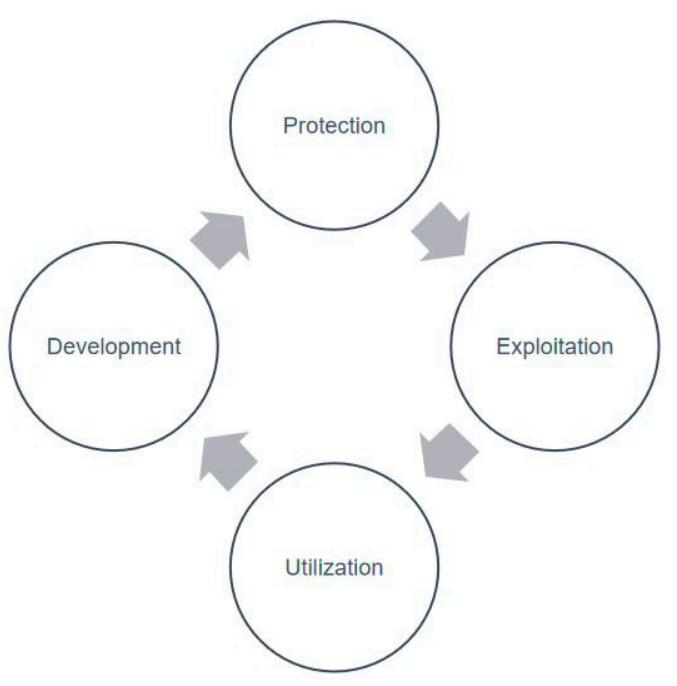

Figure 5. Benign circle of sustainable development.

\subsection{Production Factors}

\subsubsection{Prosperity of Suzhou Prefecture in the Ming Dynasty}

\section{Geographical location}

In the Ming Dynasty, the Suzhou Prefecture (also known as "Wu") belonged to South Zhili Province. Apart from Suzhou City, Suzhou Prefecture administered Wu County, Changzhou County, Changshu County, Wujiang County, Kunshan County, Jiading County, Chongming County, and Taicang County.

In 610, the Sui Dynasty started building the Beijing-Hangzhou Grand Canal, and Suzhou became the center of the Beijing-Hangzhou Grand Canal and the Loujiang River (now called the Liuhe River). Moreover, as it was located in the Yangtze River basin, it enjoyed both inland navigation and maritime transportation conveniences, which played an important role in the economic development of Suzhou.

\section{Population aggregation}

In the history of China, there were three large-scale southward population migrations before the Ming Dynasty, and they occurred successively during the Southern Migration of Aristocratic Families in the Wei, Jin, Southern, and Northern Dynasties (307-313); the Anshi Rebellion of the Tang Dynasty (755-763); and the Jingkang Rebellion of the Song Dynasty (1126-1127), respectively. With three large-scale southward population migrations, the Suzhou Prefecture became the most densely populated area in the country. In 1578, there were 600,755 households in a population of 2,011,985 in Suzhou Prefecture, ranking it first in the country [20].

In addition to the total population, the number of literati in Suzhou was first-ranked in the country. There were 24,866 successful candidates in the highest imperial examinations in the Ming Dynasty, and 3864 were from the Jiangnan region, accounting for $15.54 \%$ of the total number of candidates [25]. People in the Jiangnan region liked and were good at reading, and the Jiangnan region had the most libraries in the country. Thus, the literati gathered in the Jiangnan region.

\section{Economic prosperity}

The Ming Dynasty witnessed unprecedented prosperity in the economic and cultural development history of China. The continuous development of the commodity economy and the emergence of capitalism provided the Ming Dynasty with economic development momentum. In the Ming Dynasty, there were different market forms. According to different regional characteristics, the market frequency was not uniform and ranged from once per month to three times per month. In places such as Suzhou Prefecture and Songjiang Prefecture, the markets were different from the regular market 
stage. The market became the economic center with frequent daily trading activities and was called a fixed market [26]. Such a fixed market in the Jiangnan region also reflected the rich commodity varieties and sufficient commodity circulation volume in the region, as well as the purchasing power of local residents.

Taxation played a pivotal role in the development of the commodity economy. The Ming government did not impose heavy taxes on economically developed regions; instead, it implemented a tax exemption policy in these regions. In 1528, the emperor decided to cancel taxation on retail sales and stall keepers in Suzhou, Songjiang, Changzhou, and Zhenjiang Prefectures [27]. After the taxation of retail sales was canceled in Suzhou, Songiiang, Changzhou, and Zhenjiang Prefectures, the merchants gathered in this region, thus promoting the prosperity of a commodity economy in Suzhou.

\subsubsection{Natural Resources}

Located in the lower reaches of the Yangtze River, Suzhou faces the sea on the southeast and is situated in the temperate zone, meaning that it has a subtropical monsoon maritime climate. Suzhou is characterized by distinct seasons, mild climate, and abundant rainfall [28] (pp. 28-29). The local beechwood (Zelkova serrata, Zelkova Spach) can be divided into two types according to color and texture: orange beech with loose and clear wood grains; and red beech with fine and overlapped wood grains, which is also known as "blood beech" [29]. The ornamental and practical value of top-grade blood beech can be compared to that of rosewood. In addition to the color, texture, and hardness advantages, beech also has the advantages of a high bearing capacity and good pressure resistance. The mass production of folk beech-made furniture laid a good foundation for the sustainable development of Su-style furniture.

The production factors of Su-style furniture of the Ming Dynasty that affected its competitive advantages originated from its superior geographical location and local resources. As for today's handicrafts, each region has its own unique geographical environment. People who undertake long-term exploration of and adaptation to the surrounding environment gradually form their own unique techniques. Therefore, traditional handicrafts are usually local, unique, and accompanied by strong regional characteristics. The characteristics are often rooted in traditional culture, so the cultural industry has undoubtedly become the best carrier for the development of traditional handicrafts. At present, the sustainable development of traditional handicrafts needs to start from its own advantages and characteristics, fully tap local resources [30], and innovate on the basis of inherited tradition. Cultural and creative industries can provide inspiration, themes and resources for the creation of traditional handicrafts and open up new paths for the sustainable development of traditional handicrafts.

\subsection{Demand Conditions}

\subsubsection{Literati Demand}

The literati played a vital role in the overall development of Ming-style furniture, as they were the main users of furniture and often had a great appreciation for a high aesthetic level of furniture. They had their own ideas and individualities regarding the materials, styles, workmanship, and placement. Wen Chen-heng (1585-1645) of the Suzhou literati proposed simple, applicable, and natural aesthetic requirements for furniture in Collation of Superfluous Things (1621) (Figure 6). He defined rosewood, lignum vitae (Guaiacum, Zygophyllaceae), and Incense Nanmu (Machilus, Lauraceae) as fine wood, and he thought that furniture made of fine wood was top-grade. He believed that adding a high amount of carvings and paintings made the furniture look vulgar. A natural couch could not be engraved with vulgar patterns, such as dragons, phoenixes, flowers, and grass [31] (Figure 7). It is apparent that the aesthetic requirements of the literati were very strict and that ordinary furniture could not satisfy their requirements; therefore, the literati often personally participated in the design of furniture. 


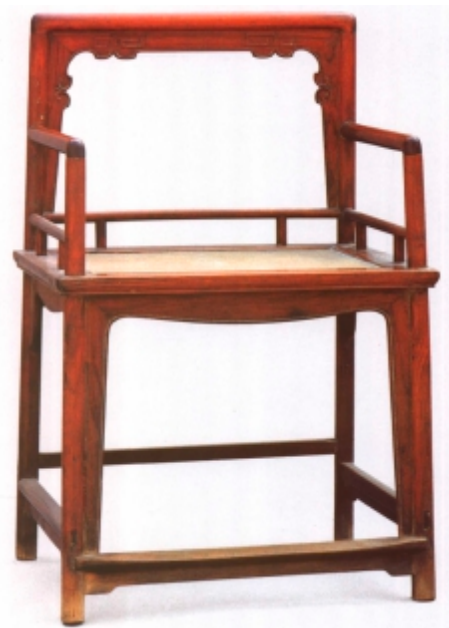

Figure 6. Rosewood armchair in the Ming Dynasty. Wang Shi-xiang, Appreciation of Ming-style Furniture, SDX Joint Publishing Company \& Cultural Relics Publishing House, 1985.
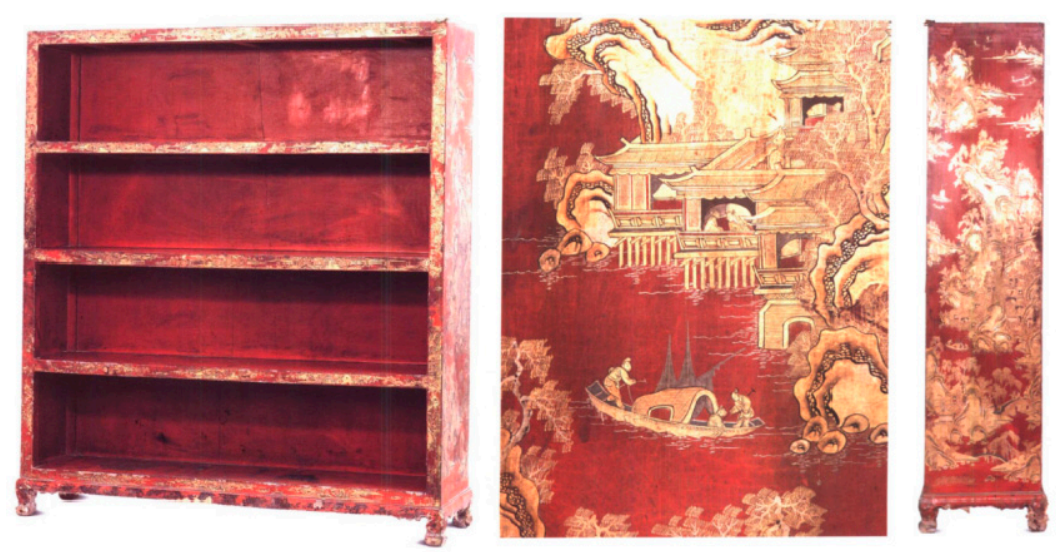

Figure 7. Golden landscape shelf with red lacquer. Zhu Jiajin, ed. Furniture of the Ming and Qing Dynasties (I), Shanghai Scientific \& Technical Publishers, 2002.

Li Yu (1611-1680) designed a separator for couches in Xian Qing Ou Ji (1671) to prevent the desktop from cracking from overheating by the winter's furnace. In addition, Li Yu invented and designed a heating chair and a cooling stool. The heating chair (Figure 8), which featured two armrests set in the front and rear, could resist the cold in winter, as carbon was placed in the drawer and covered with fine ash, which made the whole chair warm. The cooling stool (Figure 9) was similar to an ordinary stool, except that it was empty below the stool surface, the surroundings were embedded with oil ash, and cold water was poured to reduce the heat [32].

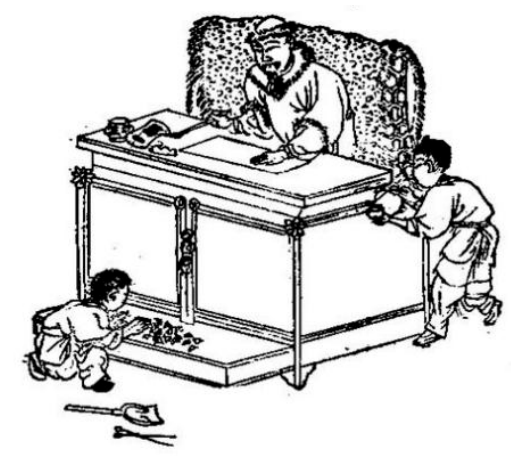

Figure 8. Heating chair. Li Yu, Xian Qing Ou Ji, China Social Press, 2005. 


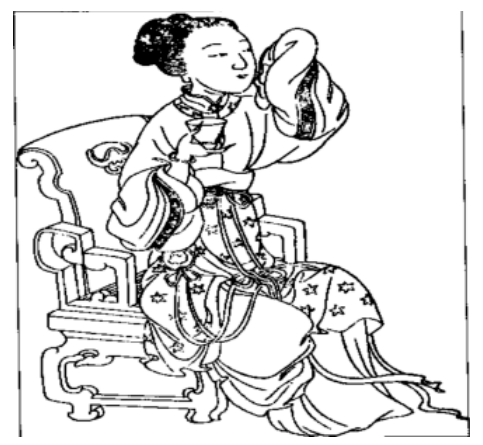

Figure 9. Cooling stool. Li Yu, Xian Qing Ou Ji, China Social Press, 2005.

In the Ming Dynasty, maiden beds, which were divided into complex and simple beds, were more popular in Suzhou. The complex maiden bed (Figure 10) was relatively closed, and although it provided better privacy, ventilation was adversely affected. The simple maiden bed (Figure 11) provided better ventilation; however, in winter, warmth was lacking. Therefore, Gao Lian improved the maiden bed and transformed the low screens on the three sides into bedside rails, thereby making the bed useable in both winter and summer. Therefore, it was named the "two-purpose bed." On summer nights, a "leakage-free net" (a bed-covering net made of coarse cloth) was hung above the bed, which could provide ventilation and keep mosquitoes outside; on winter nights, cloth or paper was added to the low screens on three sides to resist the cold [11].

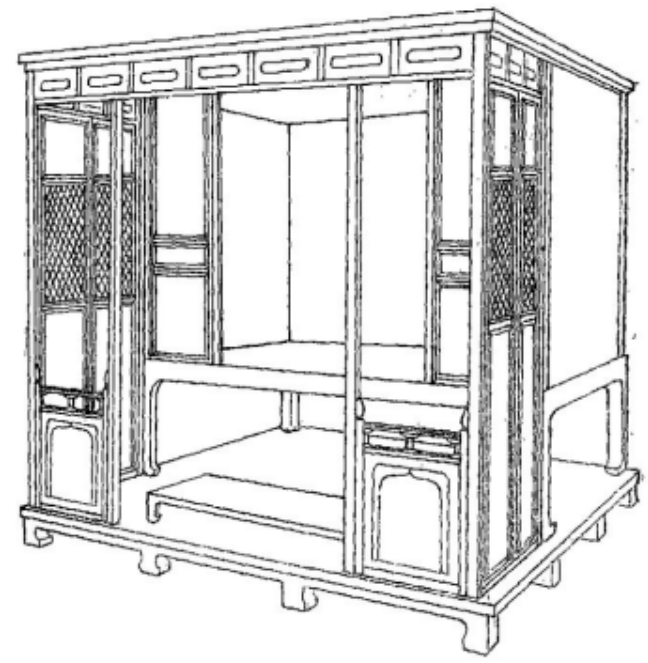

Figure 10. The complex maiden bed. 5. Wang, Shi-xiang, Lu Ban Jing Jiang Jia Jing-Interpretation to furniture articles, Journal of the Palace Museum, 1980, 3, 55-68.
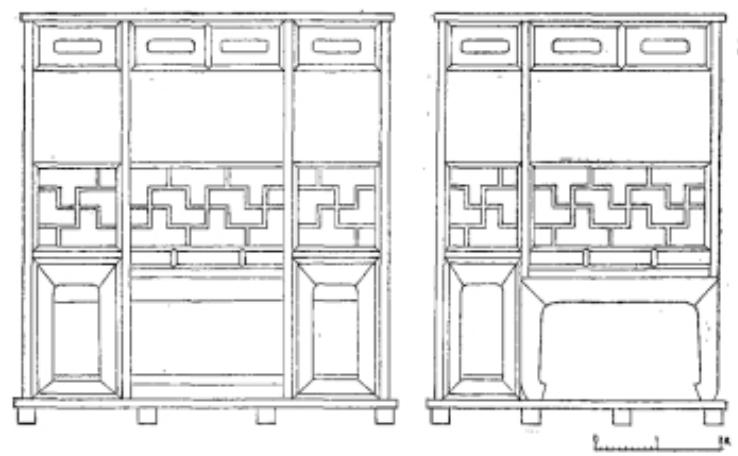

Figure 11. The simple maiden bed. Wang, Shi-xiang, Lu Ban Jing Jiang Jia Jing-Interpretation to furniture articles, Journal of the Palace Museum, 1980, 3, 55-68. 
The furniture requirements of the literati were specific and strict, and they had their own set of standards regarding material, style, pattern, function, and placement. Every detail from the length and size of the furniture to the sculpture pattern determined whether the furniture could be placed in a literati's room. It was precisely such strict requirements and literati innovation that promoted the overall development of Su-style furniture, and such pieces formed a unique, simple, and elegant style.

\subsubsection{Public Demand}

With the development of the commodity economy in the Ming Dynasty, overseas silver flowed into China. As Suzhou was one of the most prosperous metropolises at that time, the lives of Suzhou's people were significantly improved. Gu Qi-yuan (1565-1628) recorded in the Ke Zuo Zhui Yu (1617) that, at the end of the Jiajing Period, even ordinary people started building gardens, creating expensive interior decorations, and adding high-end furniture that matched their gardens [33]. Fan Lian recorded in the Yun Jian Ju Mu Chao that, during the Longqing and Wanli Period, even the poorest people used fine wood furniture [9].

The prosperity of the economy and the development of maritime trade improved the living standards of people; thus, they had increasing demands for luxury commodities, and expensive and extravagant fine wood furniture was enthusiastically purchased by the people. The aesthetics of ordinary people were mainly concentrated on luxury and wealth. Therefore, while the Su-style furniture is simple, beautiful, natural, and elegant, it consists of valuable hardwood such as rosewood as raw material.

It is clear that meeting the needs of consumers is the first step toward the sustainable development of Su-style furniture of the Ming Dynasty. Vigorous literati demand prompted its makers to improve and innovate styles and technologies, so as to better adapt to the environment at that time. The current demand conditions, on the one hand, refer to the material needs of consumers for handicraft products and, on the other hand, refer to the spiritual needs of consumers for traditional cultural connotation. It is precisely because of the unique cultural connotation of traditional handicrafts that they have become a unique cultural product in consumer society [34]. In order to achieve sustainable development, traditional handicrafts should not only meet the needs of practicability and functionality in the market but also give full play to their own characteristics to meet people's diverse spiritual and cultural needs. However, current traditional handicraft artisans usually integrate design, production, and sales into one, but they lack innovation ability. The variety is limited, and the style is outdated. Therefore, the traditional handicraft needs to be integrated into modern designs to form a mode of cooperation between craftsmen and designers, seek cultural connotation from traditional culture, and combine modern people's lifestyle to enhance aesthetic appreciation and create products compatible with current trends.

\subsection{Related Industries and Supporting Industries}

\subsubsection{Tool Manufacturing}

Many processes, such as cutting, selection, tenon-and-mortise work, and assembly, are required in the manufacturing process of wooden furniture, and each process requires corresponding tools. The main tools required for woodworking are saws, axes, planes, ink fountains, drills, chisels, hammers, shovels, and Luban rulers, which are all iron-made; there are several famous iron tool production areas in the Suzhou region, including Duncun City of Wujiang County and Tanqiu City of Zhenze County (formerly Wujiang County, Suzhou Prefecture) which created advantages and convenience for the overall woodworking industry of Suzhou. The development of the iron-made tool manufacturing industry was one of the reasons for the long-term sustainable development of Su-style furniture. 


\subsubsection{Wood Transportation and Trade}

It is particularly important for furniture manufacturing to select good-quality raw materials. Suzhou is located in the middle and lower reaches of the Yangtze River. In the early Ming Dynasty, beech was used as the main raw material; in the middle and later stages, other hardwoods were used and transported from all over the country, and even from overseas. Wood transportation in Suzhou was mainly based on waterways and maritime transportation, and waterway transportation was mostly in the form of rafting or shipping. The wood was braided and then transported. Valuable wood and processed wood were primarily transported by shipping, as it was safer and more reliable.

Most maritime transportation was based on sailboats, and most of the wood delivered to Jiangnan from Fujian was shipped by sea. The sizes and loading capacities of the ships were different small-sized ships carried about 80-100 large wood pieces; medium-sized ships carried about 100-150 large wood pieces; large-sized ships carried about 300-400 large wood pieces [35].

The surrounding areas of Suzhou, including Nanjing, Hangzhou, and Shanghai, were all developed from the wood trade. The Shangxin River of Nanjing was a famous wood market, as well as a place where wood was distributed and Huizhou wood merchants gathered. The wood trade in Shanghai was very developed, and both domestic and imported wood could be found. The hardwood imported from the southern archipelago and India also became high-grade materials used for furniture or buildings.

\subsubsection{Shipbuilding Industry}

In the Ming Dynasty, the shipbuilding industry developed rapidly, and most of the wood, grains, and other goods in the Jiangnan region were transported by water: thus, ships became an indispensable means of transportation. Because the shipyards required a high amount of wood for shipbuilding, and since the finished ships could transport wood all over the country for sale, the shipbuilding industry and the wood trade complemented each other.

In the areas surrounding Suzhou in the Ming Dynasty, there were five shipyards in Nanjing, namely, Bao Shipyard, Longiiang Shipyard, Huang Shipyard, Nanjing Shipyard, and Bo Shipyard. Bao Shipyard was mainly responsible for the manufacture of sea ships; Longjiang Shipyard was mainly responsible for the manufacture of grain transportation ships; Huang Shipyard was royally affiliated and mainly responsible for the manufacture of the emperor's royal ships; Nanjing Shipyard was also called the Horse Shipyard. The ships of these four shipyards were originally designed to transport horses and later converted to transport cargo. Bo Shipyard was mainly responsible for repairing ships [36]. It is apparent that the scale of the shipbuilding industry in the Ming Dynasty was huge, and the labor responsibilities were clearly specified, forming an overall ordered system. This reasonable organization and labor division promoted the continuous improvement of the productivity of the shipbuilding industry.

The Exploitation of the Works of Nature (1637) also recorded that, in West Zhejiang, there were trillions of ships in the deep ditches and small water bays within 700 li of Suzhou [37], and this fully shows that the transportation and shipbuilding industry of Suzhou and surrounding areas was developed.

The development of the Su-style furniture of the Ming Dynasty cannot be separated from the support and assistance of tools, wood, and shipbuilding industries. The benign development of industries can be promoted by the development of related industries. Therefore, good related supporting industries are an important driving force for the sustainable development of the traditional handicraft industry. Perfectly related supporting industries can provide raw material supply networks and a firm market for the handicraft industry [38]. Therefore, in order to achieve the real sustainable development of traditional handicrafts, it is necessary to develop its related industries at the same time and form a supporting industrial chain so that all industries promote each other and develop together. 


\subsection{Peer Competition}

In the early Ming Dynasty, there were no relatively independent industrial sectors for furniture manufacturing, and the traditional family-style handicraft workshops were still dominant. It was not until the late Ming and early Qing Dynasties that it began to gradually transform into an industrial model. The description of furniture shops in Suzhou by Feng Meng-long (1574-1646) in Xing Shi Heng Yan (1627) indicates that there was a furniture shop at the Huanghua Pavilion outside Chang Men of Suzhou. On the white powder wall, there were two lines of characters that stated that the fine and stable wooden furniture by Zhang Yangting in Jiangxi never let customers down [39]. It can be seen that the production of Suzhou furniture was very common and the merchants even used advertisements to attract customers and compete with their peers. Fan Lian also described the scenes in which furniture craftsmen from Huizhou and other regions opened shops in Suzhou [9].

After the middle Ming Dynasty, with the continuous development of a commodity economy, the trade between merchants and craftsmen in various places became more frequent, and horizontal competition was intensified. Many handicraftsmen in Suzhou gathered and gradually established the merchant and trade association for different regions and different industries. Under the management of such industrial associations, there were certain regulations and constraints placed on the industry; for example, a shop opening or apprentice recruitment of both locals and foreigners had to be approved by publicly consulting the industrial association, and this approval required the payment of money. In the meantime, industrial associations undertook the corresponding pensions, medical care, funerals, and burials of the industrial craftsmen [40]. These practices had the same effect as today's medical insurance and pension insurance. It can be seen that, under the management of the industrial associations, the furniture manufacturing industry was developed in a more systematic and industrialized manner.

In the Ming Dynasty, the industry supervision department was composed of practitioners themselves, while the modern industry supervision was the responsibility of the government. The government should promulgate relevant laws and policies to ensure the stability of the industry, enable good industry planning, and put forward relevant safeguard systems. At the same time, it should support and train inheritors of traditional handicraft skills. The core of maintaining the sustainable development of the handicraft is, through effective management, to make the skills available to the people and provide the next generation with the rights to continue enjoyment. One of the most effective ways to achieve the sustainability of handicrafts is to ensure that the inheritors can further develop the necessary knowledge and skills [34].

\section{Conclusions and Suggestions}

\subsection{Analysis of the Competitive Advantages of Su-Style Furniture in the Ming Dynasty}

\subsubsection{Style Advantage}

The participation of the literati prompted the design and manufacture of Suzhou furniture to enter a new stage, which was unprecedented across the whole country. The literati advocated nature, simplicity, freshness, and elegance, and they integrated their pursuit of beauty and art with the design of furniture. Their high requirements for furniture style and quality led to the leap-forward development of furniture manufacturing in Suzhou. The literati in the Ming Dynasty brought new inspiration and vitality to the design of Suzhou furniture, and their influence was mainly reflected in improved furniture innovation, practicability, and aesthetics.

- Innovation

Li Yu put forward in Xian Qing Ou Ji that a design should have its own individuality and should not imitate the styles of other people. It should not be constrained by the previous framework, and instead, should be innovated and changed [32]. 
With the same idea, progressively more and more literati participated in the furniture design process, modified their existing furniture, and designed a variety of new furniture pieces according to actual conditions. The new design concept of the literati had a decisive influence on furniture development in Suzhou, and the innovative design concept significantly promoted the development of Su-style furniture.

\section{- Practicability}

In furniture manufacturing, one of the purposes of the literati's reformation of the existing standards was practicability. Practicability is the principle and foundation of wares manufacturing. Therefore, the literati first reformed the old system and made innovations according to practicability. The bottom of the bookshelf was higher than the ground to prevent ground moisture from damaging the books [31]; the Chinese lute table top was hollowed out to create reverberation and increase the acoustic effect [41]. It is not difficult to see that practicability was important for the daily life of the literati; furniture must first be practical in order to become a work of art. Su-style furniture in the Ming Dynasty was practical, comfortable, and aesthetically pleasing, which became its unique advantages.

- Aesthetics

The requirements of the literati in the Ming Dynasty for furniture aesthetics were mainly simplicity and elegance, and they pursued natural and ancient styles with simple and smooth features while rejecting excessive carved decorations. In addition, they had strict requirements regarding the raw materials, patterns, sizes, and decorations of furniture; the raw wood should be precious hardwood, and the inlaid stone was divided into top and low grade. White and slightly green or black and slightly gray marble were the low-grade products [31].

The rigorous requirements of the literati in the Ming Dynasty invisibly promoted the rapid development of Su-style furniture, which gradually proliferated its own style through fierce competition. The formation of this furniture was also a concrete manifestation of the spirit of literati in material life in the Ming Dynasty. As the literati poured their feelings and spiritual expectations into their furniture, the furniture manufactured in Suzhou in the Ming Dynasty was naturally graceful, simple, elegant, quaint, and beautiful and formed unique style advantages.

\subsubsection{Material Advantage}

Due to the ban on maritime trade, most people in the early Ming Dynasty lived a self-sufficient lifestyle, and wares were produced using local materials. The wood produced in Suzhou was mainly beech. In early furniture manufacturing, beech was the most important raw material for folk furniture.

With the development of foreign trade, the commodity economy of the Ming Dynasty developed rapidly. People's living standards continuously improved, and they were no longer satisfied with ordinary beech-made furniture. Instead, they began to popularize the valuable hardwood-made furniture. Imported valuable wood mainly included rosewood, Cassia siamea (Senna, Caesalpiniaceae), and ebony (D. ebenum, Diospyros), which were the main raw materials for furniture manufacturing in Suzhou in the Ming Dynasty. The texture, grain, and color of rosewood are similar to those of beech; therefore, the craftsmen of Suzhou were the first to use rosewood in furniture manufacturing. In the initial furniture manufacturing process of the Ming Dynasty, local wood was used as the raw material for the furniture made in various regions. Early beech characteristics were similar to those of valuable hardwood; therefore, Su-style furniture was of good quality, aesthetics, and practicability in the early Ming Dynasty. In the middle stage, valuable hardwood was used all over the country; at this time, this furniture's advantage was that the craftsmen had the ability to work with valuable hardwood because of their earlier use of beech. Suzhou featured a superior geographical location, the development of the shipbuilding industry, and many large-scale wood markets in the surrounding area, as well as extremely convenient domestic and foreign wood transportation and trade. As these 
features provided excellent conditions for the acquisition of all raw materials, the material advantage of Su-style furniture was comprehensively formed.

\subsubsection{Process Advantage}

The prosperity of ware manufacturing cannot be separated from the craftsmanship of the artisans. The changes in the craftsman registration system had an important impact on almost all of the ware manufacturing industries in the Ming Dynasty. Craftsmen devoted themselves to their respective works, which promoted the benign development of all industries.

Some of the craftsmen relieved from labor service chose to return to their hometown, while some sought work opportunities in the big cities. Because of its economic prosperity, sound urban scale, large population, and rich work opportunities, many craftsmen came to work and live in Suzhou. Therefore, a large number of foreign craftsmen joined in the industrial competition in Suzhou in the Ming Dynasty. Employers had more choices in terms of their workers, resulting in competition in furniture manufacturing in Suzhou. Suzhou craftsmen were good at using the mortise method. The most typical was the curved chair backrest of Su-style furniture in the Ming Dynasty. Different curvatures can be selected according to different chair sizes, as the spines of people are S-shaped when sitting (Figure 12). As a vertical backrest affects the normal bending of the human body, as a part of a long-term exploration, the craftsmen created a curved backrest that could support the waist.

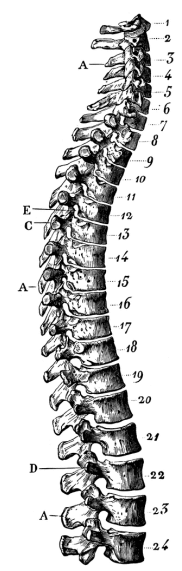

Figure 12. Human spine. Available online: http://etc.usf.edu/clipart/35300/35380/spine_35380.htm (21 November 2018).

While the back curvature of the armchair is similar to that of the human spine, it was not completely designed for this reason (Figure 13), as Suzhou craftsmen were more concerned about the practical performance of furniture. The curve angle in the opposite direction of the spine did not cause excessive fatigue; in addition, the person sitting in the chair would not become inactive because the chair was too comfortable. The back plate of the round-backed chair was not designed as an " $\mathrm{S}$ "-shaped curve but was instead based on a curve with a large curvature (Figure 14), as the round-backed chair was mainly used for rest rather than reading or working. Therefore, the large-curvature back plate increases comfort. 


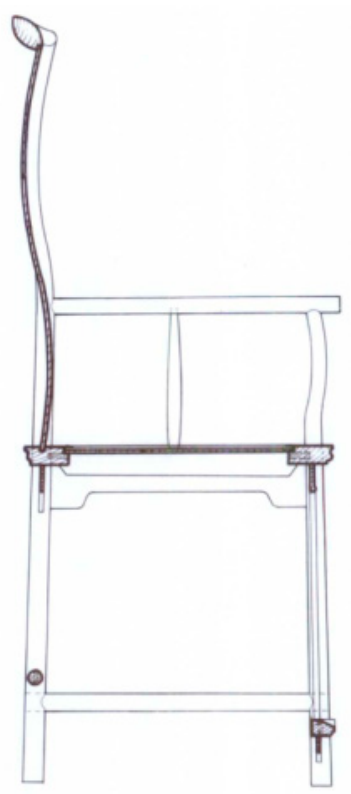

Figure 13. Actual measurement of rosewood armchair in the Ming Dynasty. Wang Shi-xiang, Appreciation of Ming-style Furniture, SDX Joint Publishing Company \& Cultural Relics Publishing House, 1985.

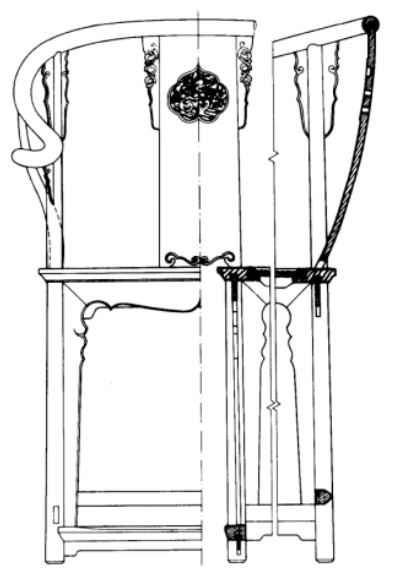

Figure 14. Actual measurement of rosewood backrest round-backed chair in the Ming Dynasty. Wang Shi-xiang, Appreciation of Ming-style Furniture, SDX Joint Publishing Company \& Cultural Relics Publishing House, 1985.

The prosperity and development of Suzhou's economy attracted more skilled craftsmen to the region. At the same time, the reform of the craftsmanship system by the Ming Dynasty government and the rigorous demands of the literati were all important driving forces in technological advantages.

Thus, the competitive advantages of Su-style furniture for sustainable development came from the combined promotion of all aspects. No single aspect of development achieved the sustainable development of the whole industry. Similarly, the sustainable development of today's traditional handicrafts also needs to be jointly accomplished by uniting all aspects.

\subsection{Sustainable Development Strategy of Traditional Handicraft Industry}

The industrial competitive advantages of Su-style furniture in the Ming Dynasty were the result of multiple factors; its competitive advantages were rooted in style, material, and process. A quaint and exquisite style with few carvings and a practical and comfortable design and production with both aesthetic and cultural considerations are this furniture's most prominent characteristics. Strict demand 
conditions, competitive conditions, developed production factors, related industries, and supporting industries are the key reasons for the its development. Meanwhile, the policies and social prosperity of the Ming Dynasty provided the necessary assistance for its competitive development. Thus, it has sustained development over hundreds of years.

The study of the competitive advantages of Su-style furniture in the Ming Dynasty found that government functions were important for industrial sustainable development. While pure internal industrial transformation and innovation can provide the industry with competitive advantages in a certain social context, they are not enough to cope with changes in the social environment. The government can provide the social conditions that promote the sustainable development of the industry. In addition, product manufacturing must be based on consumers; thus, traditional handicraft products should also have the ability to inherit a traditional culture and meet both the spiritual and material needs of the people. Therefore, the sustainable development of the current traditional handicraft industry must be jointly completed by external government heritage protection and internal industrial transformation and innovation.

To address the current status of the handicraft industry in China, we believe that, for endangered craftsmanship to thrive, the government should adopt support policies, set up special funds, ensure the living quality and working environment of employees from an economic aspect, provide a solid guarantee for the sustainable development of the traditional handicraft industry, and formulate detailed and highly operational protection measures according to industrial characteristics. In view of the fact that modern people generally do not understand traditional culture and craftsmanship, the government should work with the media to improve the publicity of traditional culture and craftsmanship, enhance people's purchasing desire, increase people's protection awareness and initiative, form a good social atmosphere, improve the management system, and protect the intellectual property rights of traditional craftsmen to expand the market sales channels of traditional handicrafts. In addition, the government may also help the traditional handicraft industry to realize international popularity and thus expand the global market of traditional Chinese culture.

Compared with family inheritance and mentorship inheritance, the social inheritance system is relatively active and effective. Social inheritance refers to the establishment of specialized schools or training institutions that enroll students from society and offer systematic courses to teach relevant craftsmanship. In terms of the current social environment, the government should increase the content of arts and crafts education in primary and secondary education, strengthen the cooperation between the traditional handicraft industry and universities, and cultivate innovative talents by virtue of university resources.

Analysis of the competitive advantages of Su-style furniture in the Ming Dynasty shows that the demand condition is an important factor for the vigorous and sustainable development of any industry. As consumers have the most direct impact on the sustainable development of an industry, the current traditional handicraft industry must first solve the demand problem in order to realize prosperous development; thus, the most fundamental way to provide support is to increase the practicability of handicrafts and enhance the vitality of the handicraft industry.

People's aesthetics continually change with the progress of society, while traditional handicrafts always stay as a single variety with uniform traditional themes; this makes it difficult for artisans to cater to the aesthetic characteristics of modern people and thus resonate with the people. Although it is important to inherit traditions, it is necessary to innovate on the basis of modern society. Traditional handicrafts, which inherit the essence of traditional culture through artistic creation, have witnessed the history of the Chinese nation. With the development of productivity, the essence of handicrafts should be further highlighted. To integrate into the modern market, traditional handicraft products' added value, such as their cultural essence, should be emphasized, while new entry points and value points for consumption demand should be provided to satisfy diverse consumer demands.

Compared with the modern industry, the traditional handicraft industry has more folk and regional characteristics and exhibits both diversity and uniqueness. These characteristics, rooted in 
traditional culture, can undoubtedly be reproduced through creative design. Therefore, the cultural creative industry has become a support for the traditional handicraft industry. The innovative design and positioning of functions and forms as well as the materials of the emerging industry models that meet the needs of the times, can inject new vitality into the traditional handicraft industry.

The development of the traditional handicraft industry can rely on modern technology; for example, the use of mechanical tools and computer design can be appropriately increased to save labor costs and material resources and improve production efficiency. In addition, the traditional Chinese handicraft industry can be integrated with modern industry, rely on the Internet by cooperating with today's Internet-based media, and offer promotions through new media forms, thus expanding the sales channels.

The brand effect is also an important route by which the industry can enter the modern market. The establishment of a brand often exerts a centripetal force on practitioners, and this will help the traditional handicraft industry to enter the market quickly. The brand dependence and trust of modern society can also provide direction for the transformation of the traditional handicraft industry.

Author Contributions: Conceptualization: T.-T.F.; methodology: K.-K.F. and T.-T.F.; validation: T.-T.F.; formal analysis: T.-T.F; investigation: T.-T.F.; resources: T.-T.F.; writing-original draft preparation: T.-T.F.; writing-review and editing: K.-K.F.; supervision: K.-K.F.

Funding: This research was funded by the Taiwan Ministry of Science and Technology, grant number 107WFA2610438.

Acknowledgments: We would like to express our gratitude to the Taiwan Ministry of Science and Technology for providing research resources on this study.

Conflicts of Interest: The authors declare no conflict of interest.

\section{References}

1. Yang, Y.; Shafi, M.; Song, X.; Yang, R. Preservation of cultural heritage embodied in traditional crafts in the developing countries. A case study of Pakistani handicraft industry. Sustainability 2018, 10, 1336.

2. Zhang, F. Revitalizing Chinese traditional craft industry. J. Suzhou Art Des. Technol. Inst. 2005, 1, 20-23.

3. China Arts and Crafts Association \& National Arts and Crafts Industry General Survey Office. China Arts and Crafts Report: A Special Collection of the National General Survey of Arts and Crafts Industry; Beijing Arts and Crafts Publishing House: Beijing, China, 2009.

4. Gao, L. The Research of Crisis of Tradition Crafts and Cultural Transformation. Ph.D. Thesis, Xi'an Academy of Fine Arts, Xi'an, China, 2018.

5. Wang, S.-X. Lu Ban Jing Jiang Jia Jing-Interpretation to furniture articles. J. Palace Mus. 1980, 3, 55-68.

6. Gustav, E. Chinese Domestic Furniture; Seismological Press: Beijing, China, 1991.

7. Yang, Y. Research on Ming-Style Furniture; China Architecture \& Building Press: Beijing, China, 2002.

8. Wang, S.-X. Research on Ming-Style Furniture; SDX Joint Publishing Company: Shanghai, China, 2008; p. 17.

9. Fan, L. Yun Jian Ju Mu Chao; Shanghai Progress Publishing House: Shanghai, China, 1928; Volume 2.

10. Wang, S.-X. Guang Zhi Yi; Zhonghua Books: Beijing, China, 1981.

11. Gao, L. Zun Sheng Ba Jian; Bashu Books: Chengdu, China, 1988.

12. Lucie-Smith, E. The Story of Craft; China Academy of Art Press: Hangzhou, China, 2013.

13. Saptarshi, K. Cultural heritage preservation of traditional Indian art through virtual new-media. Procedia Soc. Behav. Sci. 2016, 225, 309-320.

14. Giorgio, V. Celebrity in Italy; Hubei Fine Arts Publishing House: Wuhan, China, 2003.

15. UNESCO. Traditional Craftsmanship. Available online: https://ich.unesco.org/en/traditional-craftsmanship00057 (accessed on 2 January 2019).

16. Song, Q.; Kang, P.; Hou, H.; Yang, D. A survey report on the development of Chinese traditional handicraft industry. China Collect. Econ. 2014, 35, $22-25$.

17. Michael, E.P. National Competitive Advantages; CITIC Press: Beijing, China, 2012.

18. Fu, Y. (Ed.) Newly Organized History of Ming Dynasty; People's Publishing House: Beijing, China, 1993.

19. Xu, J. (Ed.) Translation of Twenty-Four Histories-History of Ming Dynasty; Publishing House of Unabridged Chinese Dictionary: Shanghai, China, 2004. 
20. Compiling Committee of Complete Library in the Four Branches of Literature. Amendment to Complete Library in the Four Branches of Literature-Volume of Ming Dynasty; Shanghai Ancient Works Publishing: Shanghai, China, 1995.

21. Institute of History and Philology, Academia Sinica Print. Chronicle of Emperor Yingzong of the Ming Dynasty; Beijing University Library Collection: Beijing, China, 1962.

22. Chen, S.-Q. Craftsman system in Ming Dynasty. Hist. Res. 1955, 6, 61-88.

23. Institute of History and Philology, Academia Sinica Print. Chronicle of the Founding Emperor of the Ming Dynasty; Beijing University Library Collection: Beijing, China, 1962.

24. Wang, X.-G.; Jia, B. Problems and solutions regarding sustainable development of historical and cultural heritage in Central Plain. Henan Soc. Sci. 2008, 16, 33-36.

25. Zhu, B.; Xie, P. Index of Jinshi Inscriptions in the Ming and Qing Dynasties; Shanghai Ancient Works Publishing: Shanghai, China, 1980.

26. Fan, S. Research on Jiangnan Cities and Towns in the Ming and Qing Dynasties; Fudan University Press: Shanghai, China, 1990.

27. Huang, B. Global Water and Land Journey; Shanxi People's Press: Taiyuan, China, 1992.

28. Wang, W. Research on the Urban History of Jiangnan in the Ming and Qing Dynasties-Centered on Suzhou; People's Publishing: Beijing, China, 1999; pp. 28-29.

29. Pu, A.-G. Research on Su-Style Furniture in the Ming and Qing Dynasties; Hunan Fine Arts Publishing: Changsha, China, 2009.

30. Yang, Y. Intangible Culture's Sustainable Development and Local Design Innovation. Master's Thesis, Hunan University, Changsha, China, 2008.

31. Wen, Z. Collation of Superfluous Things; Jiangsu Science \& Technology Press: Nanjing, China, 1984.

32. Li, Y. Xian Qing Ou Ji; China Social Press: Beijing, China, 2005.

33. Gu, Q. Jian Ye Feng Su Ji, Ke Zuo Zhui Yu; Zhonghua Books: Beijing, China, 1987; Volume 5, pp. $169-170$.

34. Xie, Y. Three strategies for the sustainable development of the traditional craftsmanship: A case study on Sichuan Jiajiang manual papermaking skill. Ecol. Econ. 2014, 2, 79-83.

35. Liang, M. Research of Wood Commodity Economy in the Ming and Qing Dynasties. Ph.D. Thesis, Beijing Forestry University, Beijing, China, 2008.

36. Liu, Y. Research on shipyards in Nanjing in the Ming Dynasties. J. Marit. Hist. Stud. 2010, 1, 31-54.

37. Song, Y. The Exploitation of the Works of Nature; Yuelu Publishing: Changsha, China, 2002.

38. Liu, A.; Liu, W. Strategic thinking about Chinese appliance industrial clusters' upgrading_Taking Qingdao home appliance industry cluster for example. J. Cent. South Univ. Soc. Sci. 2011, 17, 133-140.

39. Feng, M.-L. Xing Shi Heng Yan; Hainan Publishing: Haikou, China, 1993; Volume 20, pp. 312-354.

40. Suzhou Museum. Collection of Industrial and Commercial Inscriptions in Suzhou in the Ming and Qing Dynasties; Jiangsu People's Press: Nanjing, China, 1981.

41. Wang, Z. New Ge Gu Yao Lun; Zhejiang People's Fine Arts Publishing: Hangzhou, China, 2011. 